\title{
ANALISIS PENGARUH TINGKAT PENGANGGURAN TERBUKA DAN INDEKS PEMBANGUNAN MANUSIA TERHADAP KEMISKINAN DI PROVINSI JAWA TENGAH
}

\section{ANALYSIS OF THE INFLUENCE OF OPEN UNEMPLOYMENT LEVELS AND HUMAN DEVELOPMENT INDEX ON POVERTY IN CENTRAL JAVA PROVINCE}

\author{
Indah Purboningtyas ${ }^{1)}$, Indah Retno Sari ${ }^{1)}$, Tian Guretno ${ }^{1)}$, Ari Dirgantara ${ }^{1)}$, Dwi \\ Agustina $^{1)^{*}}$, M Al Haris ${ }^{2)}$ \\ ${ }^{1)}$ Mahasiswa Program Study S1 Statistika, Fakultas Matematika dan Ilmu Pengetahuan Alam \\ Universitas Muhammadiyah Semarang \\ *dwiagstina@gmail.com \\ ${ }^{2)}$ Dosen Program Study S1 Statistika, Fakultas Matematika dan Ilmu Pengetahuan Alam Universitas \\ Muhammadiyah Semarang
}

\begin{abstract}
This study aims to examine and analyze the effect of the open unemployment rate and human development index on poverty in the Province of Central Java. This type of data uses secondary data obtained from Central Java BPS and journals as research support. This research uses multiple linear model regression tests. Regression result shows that the resulting value of poverty regression $=75.27654+0.01877($ OUR $)-0,894($ HDI $)$, The result shows that the level of Open Unemployment Rate (OUR) has a significant effect on poverty levels in Central Java Province in 2010-2019, Human Development Index (HDI) had no effect on poverty levels in Central Java Province in 2010-2019 and the Open Unemployment Rate(OUR) and Human Development Index (HDI) had no effect on the poverty rate in 2010-2019. And the coefficient of determination or R-Square of 0.9445. that means the Open Unemployment Rate(OUR) and Human Development Index (HDI) variables can explain the poverty variable by $94.45 \%$, while other variables explain the remaining $5.5 \%$.
\end{abstract}

Keywords: Poverty, Open Unemployment Rate, Human Development Index, Multiple Linear Regression Methods

\begin{abstract}
ABSTRAK
Penelitian ini bertujuan untuk menguji dan menganalisis pengaruh tingkat pengangguran terbuka dan indeks pembangunan manusia terhadap kemiskinan di Provinsi Jawa Tengah. Jenis data menggunakan data sekunder yang diperoleh dari BPS Jawa Tengah dan jurnal sebagai penunjang penelitian. Penelitian ini menggunakan metode regresi linear berganda. Hasil regresi menunjukan bahwa nilai yang dihasilkan regresi kemiskinan = $75.27654+0.01877($ TPT) -0.894 (IPM), Hasil menunjukan tingkat pengangguran terbuka (TPT) berpengaruh signifikan terhadap tingkat kemiskinan di Provinsi Jawa Tengah tahun 2010-2019, Indeks pembangunan Manusia (IPM) tidak berpengaruh terhadap tingkat kemiskinan di Provinsi Jawa Tengah tahun 2010-2019, dan Tingkat Pengangguran Terbuka (TPT) dan Indeks pembangunan Manusia (IPM) tidak berpengaruh terhadap tingkat kemiskinan tahun 2010-2019. Serta koefisien determinasi atau R-Square sebesar 0.9445. itu artinya variable TPT dan IPM mampu menjelaskan
\end{abstract}


variable kemiskinan sebesar 94,45\%, sedangkan $5,5 \%$ sisanya dijelaskan oleh variable lain.

Kata kunci: Kemiskinan,Tingkat Pengangguran Terbuka,Indeks Pembangunan Manusia, Metode Regresi Linear Berganda

\section{PENDAHULUAN}

Kemiskinan didefinisikan sebagai suatu standar hidup yang rendah yaitu suatu tingkat kekurangan materi pada sejumlah atau segolongan orang dibandingkan dengan standar kehidupan yang umum berlaku dalam masyarakat bersangkutan (Suparlan, 1984). Kemiskinan merupakan hal yang kompleks terjadi di Negara Indonesia termasuk di Provinsi Jawa Tengah. Jumlah kemiskinan Provinsi Jawa Tengah dari tahun 2010 sampai 2019 mengalami fluktuatif. Untuk melihat lebih jelasnya jumlah kemiskinan Provinsi Jawa Tengah, dapat dilihat pada grafik berikut :

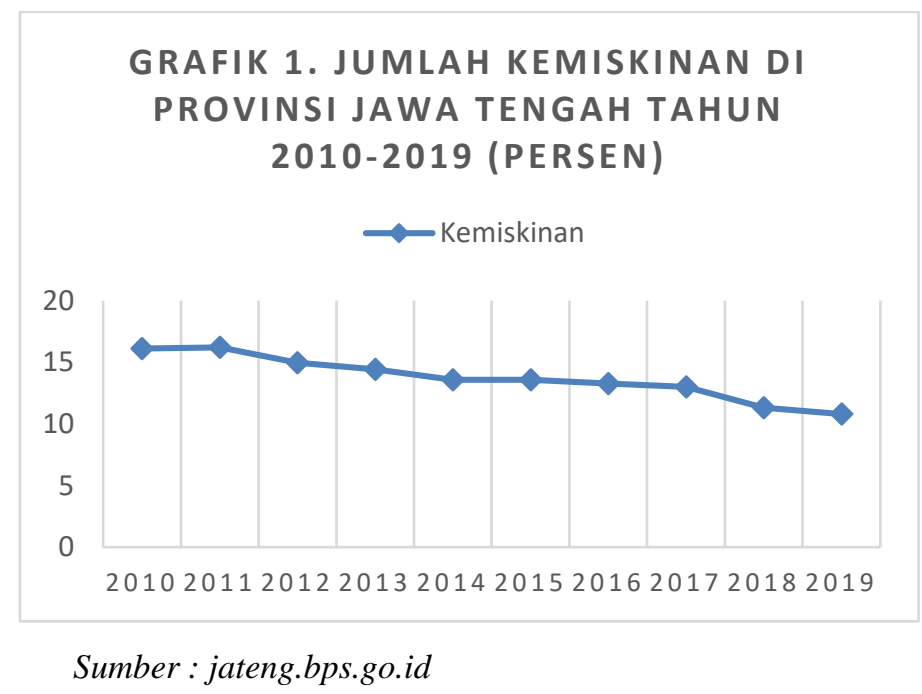

Dapat kita lihat dari Grafik1 Badan Pusat Statistik Provinsi Jawa Tengah mencatat bahwa peningkatan tertinggi Tingkat Kemiskinan di Provinsi Jawa Tengah terjadi pada tahun 2011 yaitu sebesar 16,21\%. Kemudian ditahun 2012 sampai dengan 2019 cenderung mengalami penurunan mencapai 10,80\% atau sekitar 3743,23 juta penduduk miskin. Melihat data tersebut peneliti merasa tertarik untuk melihat sejauh mana pengaruh faktor Tingkat Pengangguran Terbuka dan Indeks Pembangunan Manusia terhadap Kemiskinan di Provinsi Jawa Tengah dengan menggunakan Metode Regresi Linear Berganda.

Pada Penelitian yang dilakukan oleh (Renta,2017) menyatakan bahwa IPM dan TPT berpengaruh signifikan terhadap penurunan Kemiskinan di Kabupaten dan Kota di Provinsi Jawa Timur tahun 2012-2016. Dalam melakukan Penelitian,Renta Yusti 
menggunakan Model Regresi Berganda dengan Judul "Analisis Pengaruh Indeks Pembangunan Manusia (IPM) dan Tingkat Pengangguran Terbuka(TPT) terhadap Kemiskinan Kabupaten dan Kota di Provinsi Jawa Timur".

\section{METODOLOGI PENELITIAN}

\subsection{Identifikasi Variabel}

Variabel dalam penelitian ini terdiri dari: Variabel bebas yang digunakan yaitu:

$\mathrm{X} 1$ : Tingkat Pengangguran Terbuka

X2 : Indeks Pembangunan Manusia (IPM) dan

Y : Kemiskinan Jawa Tengah Tahun 2010 - 2019

\subsection{Sumber Data}

Data yang diperoleh dalam penelitian ini menggunakan data sekunder. Data sekunder merupakan sumber data penelitian yang diperoleh peneliti secara tidak langsung melalui media perantara (diperoleh dan dicatat oleh pihak lain). Data sekunder umumnya berupa bukti, catatan atau laporan historis yang telah tersusun dalam arsip (data dokumenter) yang dipublikasikan atau yang tidak dipublikasikan. Data-data yang digunakan dalam penelitian ini diperoleh dari website Badan Pusat Statistik Jawa Tengah yaitu www.jateng.bps.go.id

\section{PEMBAHASAN}

\subsection{Deskripsi Tingkat Kemiskinan, Tingkat Pengangguran Terbuka dan Indeks}

\section{Pembangunan Manusia Provinsi Jawa Tengah pada tahun 2010-2019}

Berikut persentase penduduk Tingkat Kemiskinan, Tingkat Pengangguran Terbuka dan Indeks Pembangunan Manusia Provinsi Jawa Tengah pada tahun 2010-2019 pada tabel dibawah ini :

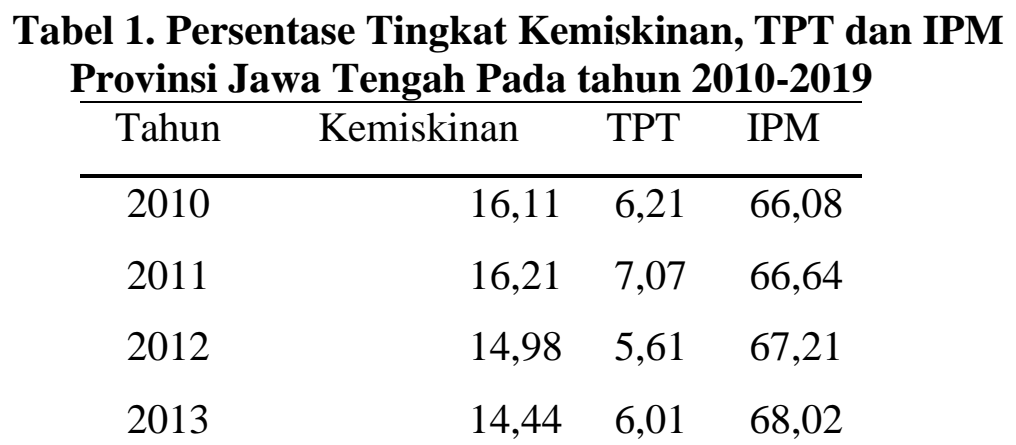




$\begin{array}{lrrr}2014 & 13,58 & 5,68 & 68,78 \\ 2015 & 13,58 & 4,63 & 69,49 \\ 2016 & 13,27 & 4,99 & 69,98 \\ 2017 & 13,01 & 4,57 & 70,52 \\ 2018 & 11,32 & 4,51 & 71,12 \\ 2019 & 10,8 & 4,49 & 71,73\end{array}$

Dari tabel diatas dapat dilihat bahwa tingkat kemiskinan Provinsi jawa tengah pada tahun 2010 sebesar 16,11\% mengalami peningkatan menjadi sebesar 16,21\% ditahun 2011. Kemudian menurun terus hingga tahun 2019 sebesar 10,8\%. Pada Tingkat Pengangguran Terbuka di Provinsi Jawa Tengah cukup berfluktuatif, dimana pada tahun 2010 Tingkat Pengangguran Terbuka Provinsi Jawa Tengah sebesar 6,21\% kemudian mengalami peningkatan di tahun 2011 sebesar 7,07\%, setelah itu menurun di tahun 2012 sebesar 5,61\%, dan meningkat kembali pada tahun 2013 sebesar 6,01\%, namun di tahun 2014 hingga tahun 2019 terus mengalami penurunan hingga 4,49\%. Dapat dilihat dari tabel diatas bahwa Indeks Pembangunan Manusia di Provinsi Jawa Tengah mengalami peningkatan dari mulai tahun 2010 sebesar 66,64\% sampai tahun 2019 sebesar 71,73\%.

\subsection{Pengujian Asumsi Klasik Variabel Tingkat Pengangguran Terbuka (Variabel Independent) dan Indeks Pembangunan Manusia(Variabel Independent), dan Kemiskinan (Variabel Dependent)}

\subsubsection{Uji normalitas}

\section{Tabel 2. One-sample Kologorov-Smirnov Test}

\begin{tabular}{cr}
\hline D & P-Value \\
\hline 0.3228 & 1.995 \\
\hline
\end{tabular}

Berdasarkan output kolmogorov smirnov hasil output spss didapatkan bahwa nilai pvalue $=0.1995>\alpha=0,05$ sehingga Ho diterima. Maka dari itu data berdistribusi normal.

\subsubsection{Uji Autokorelasi}

Hasil nilai test Durbin-Watson untuk menguji autokorelasi yaitu DW $=1.6802$. Dengan pengujian Durbin-Watson (DW) dengan ketentuan sebagai berikut (Makridakis dkk, 1983): 
Tabel 3. Kriteria Durbin Watson

\begin{tabular}{lc}
\hline \multicolumn{1}{c}{ Durbin Watson } & Pengertian \\
\hline $1,65<\mathrm{DW}<2,35$ & Tidak ada autokorelasi \\
$1,21<\mathrm{DW}<1,65$ atau $2,35<\mathrm{DW}<2,79$ & Tidak dapat disimpulkan \\
$\mathrm{DW}<1,21$ atau DW $>2,7$ & Terjadi autokorelasi \\
\hline
\end{tabular}

Tabel 4. Durbin WatsonTest

\begin{tabular}{cc}
\hline DW & P-Value \\
\hline 1.6802 & 0.2269
\end{tabular}

Berdasarkan hasil output dapat dilihat bahwa nilai DW sebesar 1.6802. maka nilai DW tersebut dalam rentang $1,65<\mathrm{DW}<2,35$, itu berarti data tersebut tidak terdapat autokorelasi.

\subsubsection{Uji Heteroskedastisitas}

Tabel 5. Hteroskedastisitas

\begin{tabular}{ccc}
\hline BP & df & P-Value \\
\hline 3.5607 & 2 & 0.1686
\end{tabular}

Berdasarkan output heteroskedastisitas, diperoleh nilai P-value sebesar 0.1686 dimana artinya $>\alpha=0,5$ yang artinya data tersebut tidak terjadi masalah heteroskedastisitas

\subsubsection{Uji Multikolinieritas}

Tabel 6. VIF

\begin{tabular}{cc}
\hline TPT & IPM \\
\hline 5.034033 & 5.03403 \\
\hline
\end{tabular}

Dari hasil output multikolinieritas didapatkan nilai VIF pada variables TPT sebesar 5.034033 dan IPM sebesar 5.034033 . Karena nilai VIF kedua variabel lebih kecil dari 10, maka dapat disimpulakan bahwa data tersebut tidak terjadi multikolinieritas. 
3.3 Analisis Regresi Pengaruh Tingkat Pengangguran Terbuka dan Indeks Pembangunan Manusia Terhadap Kemiskinan di Provinsi Jawa Tengah tahun 2010-2019

Untuk mengetahui bagaimana pengaruh Tingkat Pengangguran Terbuka dan Indeks Pembangunan Manusia terhadap Kemiskinan di Provinsi Jawa Tengah tahun 2010-2019, akan dianalisis menggunakan regresi sederhana dan pengolahan data menggunakan program R Versi 3.1.1 untuk mempermudah perhitungan.

\subsubsection{Pengujian Pertama (Uji F)}

Berdasarkan output, didapatkan nilai F sebesar 59.57 dengan nilai P-value sebesar 4,026 ( $\mathrm{p}>0,05)$ artinya variable Tingkat Pengangguran Terbuka (TPT) dan variable Indeks Pembangunan Manusia (IPM) secara simultan tidak berpengaruh terhadap tingkat kemiskinan yang ada di Jawa Tengah pada tahun 2010-2019.

\subsubsection{Pengujian kedua (Uji T)}

Hasil pengujian dengan program R menghasilkan output sebagai berikut:

\section{Tabel 7. Coefficients}

\begin{tabular}{lrrrr}
\hline & Estimate & Std. Error & $\mathrm{t}$ value & \multicolumn{1}{c}{$\operatorname{Pr}(>|\mathrm{t}|)$} \\
\hline (Intercept) & 75.27654 & 14.77194 & 5.096 & $0.00141^{* *}$ \\
TPT & 0.01877 & 0.40683 & 0.046 & 0.9645 \\
IPM & -0.894 & 0.18534 & -4.823 & $0.00191 * *$
\end{tabular}

Dari uji t, nilai nilai t-value untuk variable TPT (X1) adalah sebesar $0.046(\mathrm{p}<0,05$ ) artinya variable tingkat pengangguran terbuka berpengaruh signifikan terhadap tingkat kemiskinan diprovinsi jawa tengah pada tahun 2010-2019. Selanjutnya untuk variable $\operatorname{IPM}(X 2)$, data diatas menunjukkan nilai Sig. sebesar -4.823 ( $p>0,05)$ artinya variable IPM tidak berpengaruh terhadap tingkat kemiskinan diprovinsi jawa tengah tahun 20102019.

\subsubsection{Model Regresi}

Dari uji regresi yang telah dilakukan dapat dihasilkan model regresi:

$$
\text { Kemiskinan }=75.27654+0.01877(\text { TPT })-0.894(\text { IPM })
$$

Dari model diatas dapat diartikan jika TPT mengalami kenaikan $1 \%$ maka kemiskinan akan mengalami kenaikan sebesar 0.01877, sedangkan jika IPM naik sebesar $1 \%$ maka kemiskinan mengalami penurunan sebesar 0.894 . 


\subsubsection{Koefisien Determinasi (R-Square)}

Berdasarkan pengujian yang dilakukan, diketahui koefisien determinasi atau RSquare sebesar 0.9445. itu artinya variable TPT dan IPM mampu menjelaskan variable kemiskinan sebesar 94,45\%, sedangkan 5,5\% sisanya dijelaskan oleh variable lain.

\section{SIMPULAN}

Tingkat Pengangguran Terbuka (TPT) berpengaruh signifikan terhadap Tingkat Kemiskinan di Provinsi Jawa Tengah pada tahun 2010-2019. Indeks Pembangunan Manusia (IPM) tidak berpengaruh terhadap Tingkat Kemiskinan di Provinsi Jawa Tengah tahun 2010-2019. Tingkat Pengangguran Terbuka (TPT) dan Indeks Pembangunan Manusia (IPM) secara simultan tidak berpengaruh terhadap tingkat kemiskinan yang ada di Jawa Tengah pada tahun 2010-2019. Dari uji regresi dihasilkan model regresi Kemiskinan $=75.27654+0.01877($ TPT $)-0.894($ IPM $)$

\section{DAFTAR PUSTAKA}

Alhudori M. 2017. "Pengaruh Ipm, Pdrb Dan Jumlah Pengangguran Terhadap Penduduk Miskin Di Provinsi Jambi”. Universitas Batanghari, Jurnal Of Economics and Business Vol.1 No. 1.

Yustie Renta. 2017. "Analisis Pengaruh Indeks Pembangunan Manusia (Ipm) Danpengangguran Terbuka (TPT) Terhadap Kemiskina Kabupaten Dan Kota Di Provinsi Jawa Timur”.Fakultas Ekonomi, Universitas Wijaya Kusuma Surabaya. Hal. 49-57

Syahrani, Anisa. 2018." Analisis Pengaruh Kemiskinan, Kesehatan Dan Pendidikan Terhadap Indeks Pembangunan Manusia Dalam Perspektif Ekonomi Islam (Studi Kasus Di Kabupaten Pesawaran Tahun 2014-2016)"'SKRIPSI. Fakultas Ekonomi Dan Bisnis Islam. Universitas Islam Negeri Raden Intan. Lampung BPS Jawa Tengah.2020.Kemiskinan

(https://jateng.bps.go.id/dynamictable/2019/01/29/93/persentase-penduduk miskin-menurut-kabupaten-kota-di-provinsi-jawa-tengah-1996-2019.html. Diakses 2 Mei 2020 
BPS Jawa Tengah.2020.Tenaga Kerja

(https://jateng.bps.go.id/dynamictable/2016/12/16/34/tingkat-pengangguranterbuka-2007-2019.html. Diakses 2 Mei 2020

BPS Jawa Tengah.2020. Indeks Pembangunan Manusia.

(https://jateng.bps.go.id/dynamictable/2016/10/17/25/-metode-baru-indekspembangunan-manusia-jawa-tengah-menurut-kabupaten-kota-2010-2019.html. Diakses 2 Mei 2020 